\title{
Surgical Procedure by Type
}

National Cancer Institute

\section{Source}

National Cancer Institute. Surgical Procedure by Type. NCI Thesaurus. Code C161601.

A categorization of surgical procedures by type or purpose. 